Whole-body biodistribution and radiation dosimetry of the cannabinoid type 2 receptor ligand [11 C]-NE40 in healthy subjects

Rawaha Ahmad ${ }^{1}$, Michel Koole ${ }^{1}$, Nele Evens ${ }^{2}$, Kim Serdons ${ }^{2}$, Alfons Verbruggen ${ }^{2}$, Guy Bormans ${ }^{2}$, Koen Van Laere ${ }^{1}$

1 Division of Nuclear Medicine, University Hospital Leuven, Leuven, Belgium

2 Laboratory for Radiopharmacy, University Hospital Leuven and KU Leuven, Belgium

Corresponding author:

Rawaha Ahmad, MD

Division of Nuclear Medicine E901

University Hospital Leuven

Herestraat 49

B-3000 Leuven

Tel.: +32-16-343715

Fax: $+32-16-343759$

E-mail: rawaha.ahmad@uzleuven.be

Abbreviated title: Human dosimetry of [11 C]-NE40 for CB2R PET

Keywords: biodistribution, dosimetry, positron emission tomography, [11C]-NE40, CB2R

Disclosure: This manuscript is the peer-reviewed version of the article Ahmad R, Koole M, Evens N, Serdons K, Verbruggen A, Bormans G, Van Laere K. Whole-body biodistribution and radiation dosimetry of the cannabinoid type 2 receptor ligand [11C]NE40 in healthy subjects. Mol Imaging Biol. 2013 Aug;15(4):384-90. doi: 10.1007/s11307-013-0626-y. The final publication is available at http://link.springer.com/article/10.1007\%2Fs11307-013-0626-y 


\section{Whole-body biodistribution and radiation dosimetry of the human cannabinoid type 2 receptor ligand [11C]-NE40 in healthy subjects}

\begin{tabular}{|r|l|}
\hline Journal: & Molecular Imaging \& Biology \\
\hline Manuscript ID: & MIB-13-008-Jan-BA.R1 \\
\hline Manuscript Categories: & Brief Article \\
\hline Date Submitted by the Author: & n/a \\
\hline Complete List of Authors: & $\begin{array}{l}\text { Ahmad, Rawaha; University Hospital Leuven, Division of Nuclear Medicine } \\
\text { E901 } \\
\text { Koole, Michel; University Hospital Leuven, Division of Nuclear Medicine } \\
\text { E901 } \\
\text { Evens, Nele; University Hospital Leuven, Laboratory for Radiopharmacy } \\
\text { Serdons, Kim; University Hospital Leuven, Laboratory for Radiopharmacy } \\
\text { Verbruggen, alfons; KULeuven, Laboratory for Radiopharmacy } \\
\text { Bormans, Guy; K.U.Leuven, Laboratory for Radiopharmacy } \\
\text { Van Laere, Koen; KULeuven, Nuclear Medicine }\end{array}$ \\
\hline Keywords: & $\begin{array}{l}\text { biodistribution, dosimetry, positron emission tomography, [11C]-NE40, } \\
\text { CB2R }\end{array}$ \\
\hline & \\
\hline
\end{tabular}


Whole-body biodistribution and radiation dosimetry of the cannabinoid type 2 receptor ligand $\left[{ }^{11} \mathrm{C}\right]-\mathrm{NE40}$ in healthy subjects

Short title: Human dosimetry of $\left[{ }^{11} \mathrm{C}\right]-\mathrm{NE} 40$ for CB2R PET

Manuscript category: Brief article

To be submitted to: Molecular imaging and Biology

* Corresponding author:

Rawaha Ahmad, MD

Division of Nuclear Medicine E901

University Hospital Leuven

Herestraat 49

B-3000 Leuven

Tel.: +32-16-343715

Fax: +32-16-343759

E-mail: rawaha.ahmad@uzleuven.be 


\begin{abstract}
Purpose: The type 2 cannabinoid receptor (CB2R) is part of the human endocannabinoid system and is involved in central and peripheral inflammatory processes. In vivo imaging of the CB2R would allow study of several (neuro)inflammatory disorders. In this study we have investigated the safety and tolerability of $\left[{ }^{11} \mathrm{C}\right]-\mathrm{NE} 40$, a CB2R PET ligand, in healthy human male subjects, and determined its biodistribution and radiation dosimetry.

Procedure: Six healthy male subjects (age 20-65 years) underwent a dynamic series of 9 whole-body PET/CT scans for up to 140 minutes, after injection of an average bolus 286 $\mathrm{MBq}$ of $\left[{ }^{11} \mathrm{C}\right]-\mathrm{NE} 40$. Organ absorbed and total effective doses were calculated through OLINDA.

Results: $\left[{ }^{11} \mathrm{C}\right]-\mathrm{NE} 40$ showed high initial uptake in the spleen and a predominant hepatobiliary excretion. In the brain, rapid uptake and swift washout was seen. Organ absorbed doses were largest for small intestine and liver, with 15.6 and $11.5 \mu \mathrm{Gy} / \mathrm{MBq}$, respectively. The mean effective dose was $3.64 \pm 0.81 \mu \mathrm{Sv} / \mathrm{MBq}$. There were no changes with ageing observed. No adverse events were encountered.

Conclusions: This first-in-man study of $\left[{ }^{11} \mathrm{C}\right]-\mathrm{NE} 40$ showed an expected biodistribution compatible with lymphoid tissue uptake and appropriate fast brain kinetics in the healthy human brain, underscoring the potential of this tracer for further application in central and peripheral inflammation imaging. The ED is within the typical expected range for ${ }^{11} \mathrm{C}$ ligands.
\end{abstract}

Key words: biodistribution, dosimetry, positron emission tomography, $\left[{ }^{11} \mathrm{C}\right]-\mathrm{NE} 40, \mathrm{CB} 2 \mathrm{R}$ 


\section{Introduction}

The type 2 cannabinoid receptor (CB2R), isolated and structurally characterized in the early nineties of the past century [1], is part of the endocannabinoid system (ECS), together with the type $1(\mathrm{CB} 1 \mathrm{R})$ receptor. Both the cannabinoid type 1 (CB1R) and CB2R are G-protein coupled receptors (GPCR's), that are quite divergent in structure with only $44 \%$ overall homology [2]. In contrast to the CB1R, which is the most abundant GPCR in the central nervous system (CNS), the CB2R is widely expressed in immune-related tissues and organs, with high expression levels in spleen, tonsils and leucocytes [3]. Outside the immune system, $\mathrm{CB} 2 \mathrm{R}$ is expressed to a lesser extent in salivary gland, skeletal muscle, pancreas, ovary and testis [4-8]. In non-pathological conditions, cerebral CB2R expression is very low and only present in the cerebellum and pons [9-10]. CB2Rs are upregulated in inflammatory conditions by activated microglia, are involved in the production of nitric oxide (NO) and cytokines [11]. Furthermore, the CB2R is involved in pain processing [12].

There is accumulating evidence that the ECS is involved in the pathogenesis and clinical expression of neurodegenerative disorders, in part through the process of neuroinflammation [13-14]. Upregulation of CB2R has been described postmortem in patients with Alzheimer's disease (AD) [15], Huntington's disease (HD) [16] and Parkinson's disease (PD) [17]. Therefore, positron emission tomography (PET) imaging of CB2R in the CNS can provide a tool to investigate the in vivo importance of $\mathrm{CB} 2 \mathrm{R}$ in central inflammatory disorders.

Whereas several PET radioligands have been validated for the CB1R [18-20], only more recently attempts to radiolabel probes for CB2R have been undertaken [21]. A carbon-11labeled CB2-selective PET tracer was described but without penetration of the blood-brainbarrier (BBB) [22-23], limiting its applicability to peripheral visualization of the CB2R. Recently, we have developed and validated novel specific radioligand for CB2R PET, 2-oxo- 
7-[ $\left[{ }^{11} \mathrm{C}\right]$-methoxy-8butyloxy-1,2-dihydroquinoline-3-carboxylic acid cyclohexylamide $\left(\left[{ }^{11} \mathrm{C}\right]-\right.$ NE40). This PET ligand is fairly lipophilic (distribution coefficient $(\log \mathrm{D})$ of 3.9 and total polar surface area (tPSA) of $80.42 \AA^{2}$ ) [24]. In vitro ligand binding studies using $\underline{\text { Chinese }}$ hamster ovary $(\mathrm{CHO})$-cells expressing the human $\mathrm{CB} 2 \mathrm{R}$ have shown that NE40 has a relatively high binding affinity $(\mathrm{Ki}=9.6 \mathrm{nM})$, which was confirmed by in vivo $\mathrm{CB} 2 \mathrm{R}$ binding in mouse spleen $[22,24]$, and high specificity (100-fold over the CB1R). Radioligand safety was investigated by toxicity studies including genotoxicity (Ames test) and histopathologic evaluation in rats [25] under the microdosing concept [26]. In vivo binding in a rat model with adeno-associated viral human CB2R overexpression was confirmed [27]. Here we describe the first-in-man imaging studies, with safety and dosimetry assessment in both young and elderly male volunteers.

\section{Materials and methods}

\section{$\underline{\text { Subjects }}$}

Healthy subjects were recruited in response to an advertisement in a local community newspaper. Six healthy Caucasian male subjects were included in the study. Table 1 shows the demographic data. The subjects did not have any clinical significant medical or neurological history, and they did not have any clinically significant abnormality on physical, neurological, or laboratory examinations. In addition, they were not taking any antiinflammatory medication at the moment of the scan or during at least four weeks before the scan. The study was approved by the local Ethics Committee and conducted according to the latest guidelines of the Declaration of Helsinki. Written informed consent was obtained from all volunteers before the start of their study.

$\underline{\text { Radiotracer characteristics and preparation }\left[{ }^{11} \mathrm{C}\right]-\mathrm{NE} 40}$ 
Radiotracer preparation was performed as described previously [24]. In short, a stream of helium containing $\left[{ }^{11} \mathrm{C}\right]-\mathrm{CH}_{3} \mathrm{I}$ was bubbled through a solution of $200 \mu \mathrm{g}$ 2-oxo-7-hydroxy-8butyloxy-1,2-dihydroquinoline-3-carboxylic acid cyclohexylamide and 2-4 miligram $\mathrm{Cs}_{2} \mathrm{CO}_{3}$ in $200 \mu 1$ dimethylformamide. The reaction mixture was heated and diluted. The radiolabeled compound $\left[{ }^{11} \mathrm{C}\right]-\mathrm{NE} 40$ was collected using reversed-phase high performance liquid chromatography (HPLC). After formulation, the identity, chemical and radiochemical purity of the tracer agent $\left[{ }^{11} \mathrm{C}\right]-\mathrm{NE} 40$ were checked using HPLC. Specific activity was 363 (range 200-632) GBq/ $\mu$ mol; the maximum amount of cold NE40 injected was $<1.0$ (range 0.4-0.9) $\mu \mathrm{g}$.

\section{$\underline{\text { PET/CT procedure }}$}

All subjects fasted for at least 6 hours before PET. Subjects underwent a dynamic series of 9 whole-body PET-CT scans on a Hirez Biograph 16 PET/CT (Siemens, Erlangen, Germany) after bolus I.V. injection of $286 \mathrm{MBq}$ (range 201-325 MBq) of $\left[{ }^{11} \mathrm{C}\right]-\mathrm{NE} 40$. Data were acquired with a single energy window set at 425 to $650 \mathrm{keV}$. The first PET segment (sequential acquisition of WB scan 1 to 8 ) started simultaneously with the bolus injection and lasted for 60 minutes (time per bed position $30 \mathrm{~s}$ (for WB1-3), $60 \mathrm{~s}$ (for WB4-6) and $120 \mathrm{~s}$ (for WB7-8)). The second segment (WB9) started at 120 minutes post-injection at 4 minutes per bed position. A low-dose CT (tube potential $80 \mathrm{kV} ; 11 \mathrm{mAs}$ ) was performed before each scan segment (The additional effective dose from this CT is $0.5 \mathrm{mSv}$ (CT-Expo version 1.7, male phantom), so the subject underwent an estimated additional radiation burden of $1.0 \mathrm{mSv}$ on top of the PET study). At our center, daily quality control (QC) of the PET system is performed using a uniform ${ }^{68} \mathrm{Ge}$ cylinder to check the uniformity and the stability of the system. Cross calibration with the dose calibrator is performed at least every 3 months using a uniform ${ }^{18} \mathrm{~F}$ cylinder [28]. Moreover, we work according to the EARL FDG PET/CT

Formatted: Font: (Default) Times New Roman, 12 pt 
accreditation

program

(ResEARch

for (http://earl.eanm.org/cms/website.php?id=/en/projects/fdg_pet ct accreditation.htm). Whole-body images were reconstructed using a three-dimensional (3D) ordered-subset expectation maximization (OSEM) iterative reconstruction, with 5 iterations and 8 subsets, with CT-based attenuation and scatter correction by standard vendor-based reconstruction. No partial volume effect correction was performed.

Urine was collected after each scan segment for total urinary bladder activity determination and up to 3 hours post injection. Volume was determined by weighing the amount of urine and activity concentration was determined by measuring the activity of a defined volumetric sample of $1 \mathrm{ml}$ with a well counter Wallac 1480 wizard 14 inch (Perkin Elmer, Turku, Finland).

Safety was assessed through physical and neurological examination, vital parameter assessment, electrocardiogram (ECG), laboratory testing, and monitoring of subjective adverse experiences with telephone follow-up 24 hours and 14 days post-injection.

\section{Data Analysis}

Data were analyzed and reported accoring to the EANM guidelines for clinical dosimetry reporting [29]. Reconstructed data were analyzed using PMOD software (version 3.0; PMOD Inc., Zurich). Three dimensional VOIs were constructed on the PET emission images to include all organ activity, and their position was verified on corresponding CT images, as described previously [30]. The following organs with significant visualized activity were included as source organs: brain, gallbladder, intestines, heart, kidneys, liver, lungs, red marrow, spleen, thyroid and urinary bladder. Total tracer retention as a function of time or time-activity curves (TACs) was determined. To account for the differences in timing of each bed position, the corresponding acquisition times were calculated for each source organ, taking the bed position of the axial midposition of the organ under consideration on the 
corresponding CT scout image on which bed positions with spatial overlap are indicated. Specifically, for the axial red marrow, the midlumbar vertebral position was taken as the average time value. In this way, time-activity curves were calculated for each of the source organs indicated earlier.

To determine preliminary kinetics of brain and spleen uptake, mean standard uptake value (SUV) TACs for brain and spleen were generated.

Organ time-integrated activity coefficients (previously named 'residence times' [31]) were computed by calculating the area under the time-activity curve (TAC) of each source organ through curve fitting. Different models for different organs were used, depending on their kinetics (standardly, a bi-exponential curve was taken when the first data point was already the maximum activity point; in other cases an extra factor or term $\left(1-\exp \left(-\ln (2) x \mathrm{~T} / \mathrm{T}_{\mathrm{i}}\right)\right.$ was included to produce a better fit with a specific maximum). For heart wall, kidneys, spleen and thyroid a bi-exponential was fitted, while a mono-exponential could be used for the lungs. To account for the tracer uptake phase in brain and liver, the function $\mathrm{A}_{1} \mathrm{x}\left(1-\exp \left(-\ln (2) \mathrm{xT} / \mathrm{T}_{1}\right)\right) \mathrm{x}$ $\exp \left(-\ln (2) \times T / T_{2}\right)$ was fitted to the $\mathrm{TAC}$ while the function $\mathrm{A}_{1} \times\left(1-\exp \left(-\ln (2) \times \mathrm{T} / \mathrm{T}_{1}\right)\right) \times \exp (-$ $\left.\ln (2) \times \mathrm{T} / \mathrm{T}_{2}\right)+\mathrm{A}_{2} \mathrm{x} \exp \left(-\ln (2) \mathrm{xT} / \mathrm{T}_{\mathrm{e} 3}\right)$ was used to model the TAC of gallbladder, red marrow and remainder.

The ICRP 30 gastrointestinal (GI) model [32] was used to determine the time-integrated activity coefficients for the organs involved in the gastrointestinal tract while the voiding bladder model with a voiding interval of 2 hours was used to estimate the time-integrated activity coefficient for the urinary bladder (UB) [33]. The fraction of injected activity entering the small intestines was estimated by fitting the exponential $\mathrm{A}_{\mathrm{GI} 1}+\mathrm{A}_{\mathrm{GI} 2} \times\left(1-\exp \left(-\ln (2) \times \mathrm{T} / \mathrm{T}_{\mathrm{GI}}\right)\right)$ to the decay corrected TAC of the intestinal VOI. Total fraction for the gastrointestinal tract was determined as $\left(\mathrm{A}_{\mathrm{GI}}+\mathrm{A}_{\mathrm{GI} 2}\right)$ normalized to injected activity $\mathrm{A}_{\text {inj. }}$. The remaining fraction of 
the injected activity was considered as excreted through the urinary bladder. Biological halflife for the fraction entering the urinary bladder was estimated by fitting $\left(\mathrm{A}_{\mathrm{inj}}-\mathrm{A}_{\mathrm{GI}}-\mathrm{A}_{\mathrm{GI}}\right) \times(1-$ $\left.\exp \left(-\ln (2) \times \mathrm{T} / \mathrm{T}_{\mathrm{UB}}\right)\right)$ to the $\mathrm{TAC}$ of the urinary bladder corrected for decay and between scan voiding. Radiation exposure of the body and critical organs were calculated from the tracer time-integrated activity coefficients using the OLINDA (Organ Level Internal Dose Assessment, Vanderbilt University, USA) software package. The effective dose (ED) was calculated from the individual organ doses with a predefined weighting factor for each of the source organs [34].

\section{Results}

As for safety, all monitored clinical parameters (heart rate, blood pressure, 12-lead electrocardiogram, blood analysis) remained normal and no clinically significant adverse experiences were reported by the subjects at the time of scanning, nor were any reported during the follow-up phone interviews.

Figure 1 shows a series of coronal and sagittal whole-body slices of $\left[{ }^{11} \mathrm{C}\right]-\mathrm{NE} 40$ over time for a representative subject. The tracer was readily taken up in the liver and partially excreted through the gastrointestinal system. Some urinary tract activity was noted after a few minutes. Based on the statistics of the abdominal VOI, $10.5 \pm 7.5 \%$ of the injected activity was entering the intestines and therefore considered as cleared hepatobiliary. The remaining fraction was considered excreted through the urinary tract, with a biological urinary clearance half-life estimated at $183 \pm 96$ hours. Due to the slow urinary excretion rate, collected urinal activity from the first two patients during 3 hours post injection was very limited and therefore was not further taken into account for the calculations. Rapid uptake (to a maximum of $1.5-3 \%$ of the injected activity) and fast washout in the brain was seen, in accordance with the low CB2R expression levels in normal brain. 
Figure 2 shows relative time-activity curves for the liver, brain, gallbladder and spleen after injection of $\left[{ }^{11} \mathrm{C}\right]-\mathrm{NE} 40$. The highest variability in activity was observed in the gallbladder. $\underline{\text { In one of the subjects we observed a second peak of activity after } 40 \text { minutes post-injection }}$ (p.i.).

Time-integrated activity coefficients for all individual patients and source organs are given in Supplementary Table 1 . Table 2 summarizes organ mean radiation absorbed doses and the effective doses. Individual organ absorbed dosesdoses; average organ doses derived from individual doses as well as based on mean kinetic parameters (time-integrated activity $\underline{\text { coefficient TIAC) and their relative difference }(\%) \text { are given in Supplemental Table 2. As can }}$ be seen from this table, there is only a very small difference between both approaches. The small intestine and the liver showed the highest organ dose of 15.6 and $11.5 \mu \mathrm{Gy} / \mathrm{MBq}$, respectively, followed by the heart wall $(7.02 \mu \mathrm{Gy} / \mathrm{MBq})$. Table 1 includes the individual ED estimates for all subjects. The average ED was $3.64 \pm 0.81 \mu \mathrm{Sv} / \mathrm{MBq}$ (range 2.79 to 5.09 $\mu \mathrm{Sv} / \mathrm{MBq})$. No significant correlation between age and ED was found.

Figure 3 shows the time activity curves (standard uptake values, SUV) with activity values corrected for decay caused by the time interval between tracer injection and start time of the different whole body PET scans of the six healthy volunteers for the brain and the spleen. In the brain, a maximum between 10-20 min can be seen in some subjects, with thereafter a continuous decline of the SUV value. In the spleen, after 20 minutes a stable SUV is seen, plateauing around 1.

\section{Discussion}

Biomarkers of (neuro)inflammation can be useful as a tool in drug development and in clinical conditions for severity assessement and therapy follow-up. The CB2R is predominantly expressed in peripheral tissues and shows the highest expression levels in 
organs of the immune system [35]. In the central nervous system, CB2R is upregulated in inflammatory conditions of activated microglia. Most of the CB2R radioligands described so far are derivatives of 2-oxoquinoline class that have shown a high selectivity for CB2Rs as inverse agonists [22-24, 36-37]. Although some were promising in in vitro studies, their in vivo stability was poor with fast metabolisation. Proof-of-principle of the feasibility of CB2R imaging in pathological conditions with a neuroinflammatory component in vivo was described by Horti et al. [21]. Since $\left[{ }^{11} \mathrm{C}\right]-\mathrm{NE} 40$ showed favourable characteristics for neuroimaging, we performed this first-in-man study to assess the biodistribution and evaluate the safety of $\left[{ }^{11} \mathrm{C}\right]-\mathrm{NE} 40$.

The gallbladder showed the highest variability in activity. In one of the subjects we observed a second peak of activity after 40 minutes p.i., possibly due to an early contraction of the gallbladder, after which there is an accumulation of the activity with a second contraction. Overall the gallbladder activity can differ between subjects due to large differences in the individual kinetics of gallbladder emptying, a process influenced by multiple hormonal factors and gastrointestinal interactions.

The average injected tracer mass dose in this study was less than $1.0 \mu$ gram. There were no subjective effects or adverse events including changes in laboratory blood tests, blood pressure, pulse and ECG. The subjects in this study received a total ED of $2.1 \mathrm{mSv}$ including the PET and attenuation correction CT studies. In a recent literature overview of 32 human PET radiation dosimetry studies with ${ }^{11} \mathrm{C}$ radioligands, van der Aart et al. showed that the vast majority have an effective dose of below $9 \mu \mathrm{Sv} / \mathrm{MBq}$, with a mean of $5.9 \mu \mathrm{Sv} / \mathrm{MBq}[38]$. The effective radiation dose in our study is thus less than this average, moreover indicating that multiple PET scans can be performed in the same subject within conventionally accepted dose limits (class IIA WHO of $10 \mathrm{mSv}$ ), allowing its use in drug development and follow-up studies. 


\section{Conclusion}

$\left[{ }^{11} \mathrm{C}\right]-\mathrm{NE} 40$ results in an effective human radiation dose of $3.64 \mu \mathrm{Sv} / \mathrm{MBq}$, which is in the lower end of the range of ${ }^{11} \mathrm{C}$ - tracers. The biodistribution with spleen uptake and absence of fixed brain uptake in healthy conditions makes the tracer promising for further studies in pathological conditions.

\section{References}

1. Munro S, Thomas KL, Abu-Shaar M (1993) Molecular characterization of a peripheral receptor for cannabinoids. Nature 365:61-65.

2. Felder CC, Joyce KE, Briley EM, et al. (1995) Comparison of the pharmacology and signal transduction of the human cannabinoid $\mathrm{CB} 1$ and $\mathrm{CB} 2$ receptors. MolPharmacol $48: 443-450$.

3. Lynn AB, Herkenham M (1994) Localization of cannabinoid receptors and nonsaturable high-density cannabinoid binding sites in peripheral tissues of the rat: implications for receptor-mediated immune modulation by cannabinoids. J PharmacolExpTher 268:1612-1623.

4. Prestifilippo JP, Fernandez-Solari J, de la Cal C, et al. (2006) Inhibition of salivary secretion by activation of cannabinoid receptors. ExpBiolMed(Maywood) 231:1421-1429.

5. Cavuoto P, McAinch AJ, Hatzinikolas G, Janovska A, Game P, Wittert GA (2007) The expression of receptors for endocannabinoids in human and rodent skeletal muscle. BiochemBiophysResCommun 364:105-110.

6. Bermudez-Silva FJ, Suarez J, Baixeras E, et al. (2008) Presence of functional cannabinoid receptors in human endocrine pancreas. Diabetologia 51:476-487.
Formatted: Font: Not Italic Formatted: Line spacing: Double, Border: Bottom: (No border) 
7. El-Talatini MR, Taylor AH, Elson JC, Brown L, Davidson AC, Konje JC (2009) Localisation and function of the endocannabinoid system in the human ovary. PLoSONE 4:e4579.

8. Liu QR, Pan CH, Hishimoto A, et al. (2009) Species differences in cannabinoid receptor 2 (CNR2 gene): identification of novel human and rodent $\mathrm{CB} 2$ isoforms, differential tissue expression and regulation by cannabinoid receptor ligands. Genes Brain Behav 8:519530.

9. Onaivi ES (2006) Neuropsychobiological evidence for the functional presence and expression of cannabinoid CB2 receptors in the brain. Neuropsychobiology 54:231-246.

10. Van Sickle MD, Duncan M, Kingsley PJ, et al. (2005) Identification and functional characterization of brainstem cannabinoid CB2 receptors. Science 310:329-332.

11. Ehrhart J, Obregon D, Mori T, et al. (2005) Stimulation of cannabinoid receptor 2 (CB2) suppresses microglial activation. JNeuroinflammation 2:29.

12. Curto-Reyes V, Llames S, Hidalgo A, Menendez L, Baamonde A Spinal and peripheral analgesic effects of the CB2 cannabinoid receptor agonist AM1241 in two models of bone cancer-induced pain. BrJPharmacol 160:561-573.

13. Bisogno T, Di Marzo V (2008) The role of the endocannabinoid system in Alzheimer's disease: facts and hypotheses. Curr Pharm Des 14:2299-3305.

14. Pazos MR, Sagredo O, Fernandez-Ruiz J (2008) The endocannabinoid system in Huntington's disease. Curr Pharm Des 14:2317-2325.

15. Benito C, Nunez E, Tolon RM, et al. (2003) Cannabinoid CB2 receptors and fatty acid amide hydrolase are selectively overexpressed in neuritic plaque-associated glia in Alzheimer's disease brains. J Neurosci 23:11136-11141.

16. Palazuelos J, Aguado T, Pazos MR, et al. (2009) Microglial CB2 cannabinoid receptors are neuroprotective in Huntington's disease excitotoxicity. Brain 132:3152-3164. 
17. Price DA, Martinez AA, Seillier A, et al. (2009) WIN55,212-2, a cannabinoid receptor agonist, protects against nigrostriatal cell loss in the 1-methyl-4-phenyl-1,2,3,6tetrahydropyridine mouse model of Parkinson's disease. Eur J Neurosci 29:2177-2186.

18. Burns HD, Van Laere K, Sanabria-Bohorquez S, et al. (2007) [18F]MK-9470, a positron emission tomography (PET) tracer for in vivo human PET brain imaging of the cannabinoid-1 receptor. ProcNatlAcadSciUSA 104:9800-9805.

19. Donohue SR, Varnas K, Jia Z, Gulyas B, Pike VW, Halldin C (2009) Synthesis and in vitro autoradiographic evaluation of a novel high-affinity radioiodinated ligand for imaging brain cannabinoid subtype-1 receptors. BioorgMed ChemLett 19:6209-6212.

20. Horti AG, Van Laere K (2008) Development of radioligands for in vivo imaging of type 1 cannabinoid receptors (CB1) in human brain. Curr Pharm Des 14:3363-3383.

21. Horti AG, Gao Y, Ravert HT, et al. (2010) Synthesis and biodistribution of [11C]A836339, a new potential radioligand for PET imaging of cannabinoid type 2 receptors (CB2). Bioorganic \& medicinal chemistry 18:5202-5207.

22. Evens N, Bosier B, Lavey BJ, et al. (2008) Labelling and biological evaluation of [(11)C]methoxy-Sch225336: a radioligand for the cannabinoid-type 2 receptor. Nucl Med Biol 35:793-800.

23. Gao M, Wang M, Miller KD, Hutchins GD, Zheng QH (2010) Synthesis and in vitro biological evaluation of carbon-11-labeled quinoline derivatives as new candidate PET radioligands for cannabinoid $\mathrm{CB} 2$ receptor imaging. Bioorganic \& medicinal chemistry 18:2099-2106.

24. Evens N, Muccioli GG, Houbrechts N, et al. (2009) Synthesis and biological evaluation of carbon-11- and fluorine-18-labeled 2-oxoquinoline derivatives for type 2 cannabinoid receptor positron emission tomography imaging. Nucl Med Biol 36:455-465. 
25. Evens N, Vandeputte C, Coolen C, et al. (2012) Preclinical evaluation of [11C]NE40, a type 2 cannabinoid receptor PET tracer. NuclMedBiol 39:389-399.

26. Ames BN, McCann J, Yamasaki E (1975) Methods for detecting carcinogens and mutagens with the Salmonella/mammalian-microsome mutagenicity test. MutatRes 31:347364.

27. Evens N, Vandeputte C, Muccioli GG, et al. (2011) Synthesis, in vitro and in vivo evaluation of fluorine-18 labelled FE-GW405833 as a PET tracer for type 2 cannabinoid receptor imaging. Bioorganic \& medicinal chemistry 19:4499-4505.

28. Boellaard R, O'Doherty MJ, Weber WA, et al. (2010) FDG PET and PET/CT: EANM procedure guidelines for tumour PET imaging: version 1.0. European journal of nuclear medicine and molecular imaging 37:181-200.

29. Lassmann M, Chiesa C, Flux G, Bardies M, Committee ED (2011) EANM Dosimetry Committee guidance document: good practice of clinical dosimetry reporting. European journal of nuclear medicine and molecular imaging 38:192-200.

30. Van Laere K, Koole M, Sanabria Bohorquez SM, et al. (2008) Whole-body biodistribution and radiation dosimetry of the human cannabinoid type-1 receptor ligand $18 \mathrm{~F}$ MK-9470 in healthy subjects. JNuclMed 49:439-445.

31. Bolch WE, Eckerman KF, Sgouros G, Thomas SR (2009) MIRD pamphlet No. 21: a generalized schema for radiopharmaceutical dosimetry--standardization of nomenclature. J Nucl Med 50:477-484.

32. Protection ICoR (1979) Limits for Intakes of Workers New York: Pergamon Press.

33. Cloutier RJ, Smith SA, Watson EE, Snyder WS, Warner GG (1973) Dose to the fetus from radionuclides in the bladder. Health physics 25:147-161.

34. Icrp (1991) ICRP Publication 60 : Recommendations of the International Commission on Radiological Protection. Oxford, UK: Pergamon Press. 
35. Maccarrone M, Battista N, Centonze D (2007) The endocannabinoid pathway in Huntington's disease: A comparison with other neurodegenerative diseases. ProgNeurobiol $81: 349-379$.

36. Raitio KH, Savinainen JR, Nevalainen T, Jarvinen T, Vepsalainen J (2006) Synthesis and in vitro evaluation of novel 2-oxo-1,2-dihydroquinoline CB2 receptor inverse agonists. ChemBiolDrug Des 68:334-340.

37. Turkman N, Shavrin A, Paolillo V, et al. Synthesis and preliminary evaluation of [18F]-labeled 2-oxoquinoline derivatives for PET imaging of cannabinoid CB2 receptor. NuclMedBiol 39:593-600.

38. van der Aart J, Hallett WA, Rabiner EA, Passchier J, Comley RA Radiation dose estimates for carbon-11-labelled PET tracers. NuclMedBiol 39:305-314. 


\section{Figure Legends}

Figure 1: Whole-body coronal and mid-sagittal PET-CT sections of [ $\left.{ }^{11} \mathrm{C}\right]-\mathrm{NE} 40$ in subject 2 (uncorrected for decay, in $\mathrm{kBq} / \mathrm{cc}$ ). Data are normalized in the same scale on a maximum activity given in the bottom row, in order to better visualize the relative distribution. Upper row indicates start time ( $\mathrm{min})$ of whole-body scan.

Figure 2: Mean activity over time in brain, spleen, liver and gallbladder as fraction of totalbody activity for all subjects.

Figure 3: Decay-corrected țime activity curves (expressed in standard uptake value (SUV); activity values decay corrected relative to the time of tracer injection) of the spleen and the brain for the 6 volunteers. 
Figure 1: Whole-body coronal and mid-sagittal PET-CT sections of [11C]-NE40 in subject 2 (uncorrected for decay, in $\mathrm{kBq} / \mathrm{cc}$ ). Data are normalized in the same scale on a maximum activity given in the bottom row, in order to better visualize the relative distribution. Upper row indicates start time (min) of whole-body scan. $114 \times 85 \mathrm{~mm}(300 \times 300$ DPI $)$

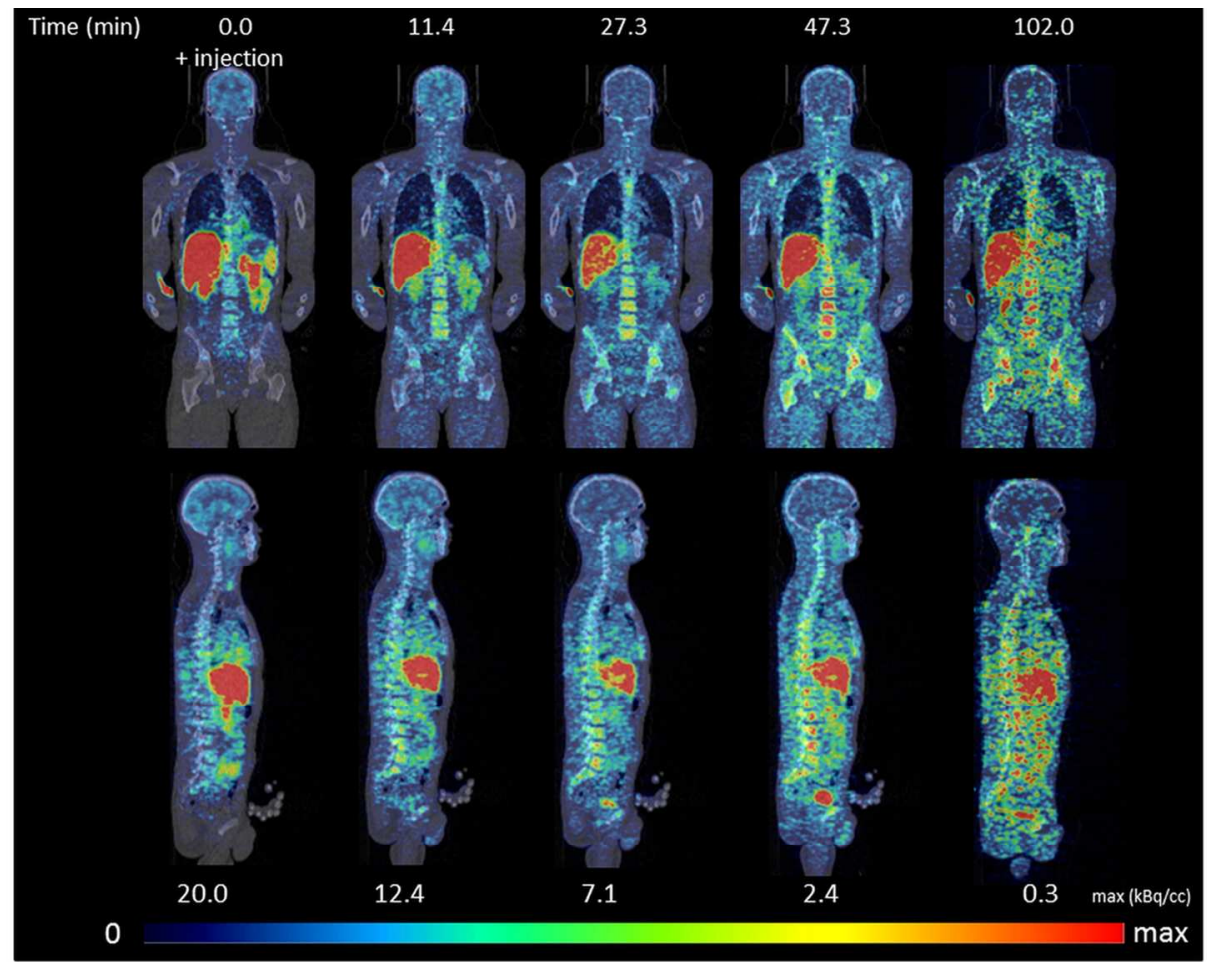

$114 \times 85 \mathrm{~mm}(300 \times 300 \mathrm{DPI})$ 


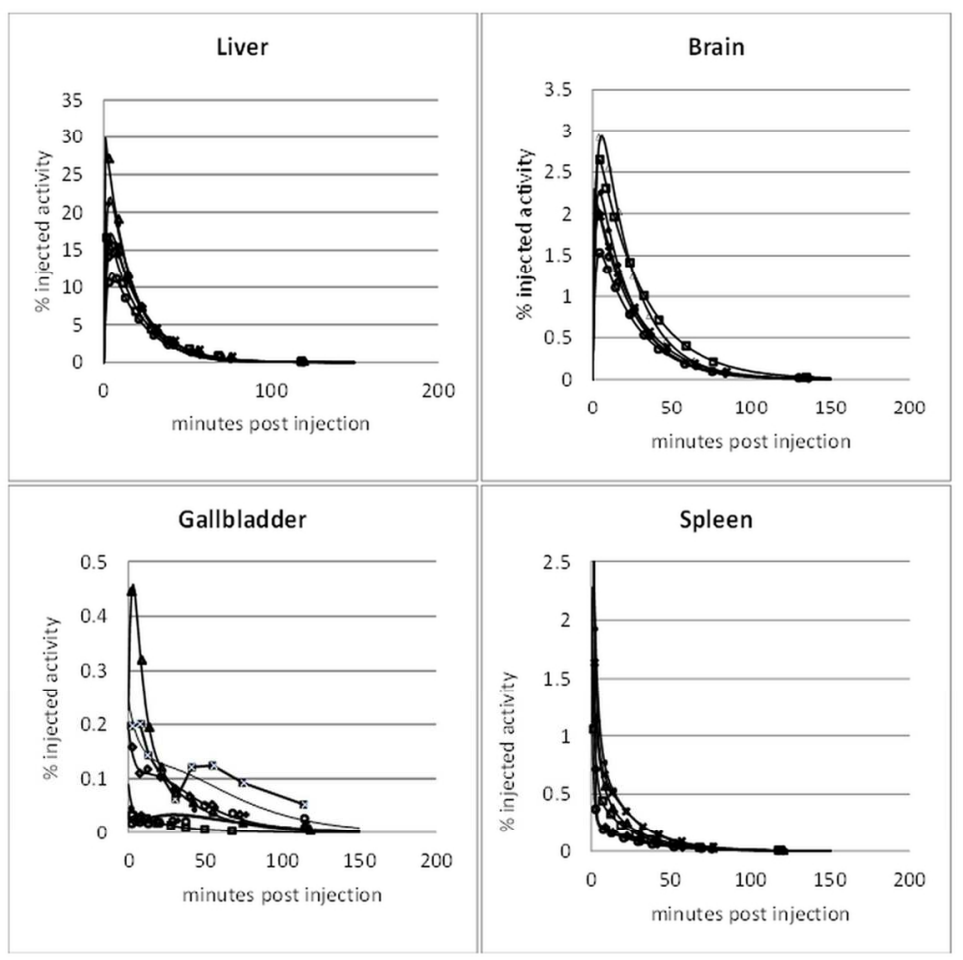

Figure 2: Mean activity over time in brain, spleen, liver and gallbladder as fraction of total-body activity for all subjects.

$114 \times 85 \mathrm{~mm}(300 \times 300 \mathrm{DPI})$ 
Figure 3: Time activity curves (expressed in standard uptake value (SUV); activity values decay corrected relative to the time of tracer injection) of the spleen and the brain for the 6 volunteers. $114 \times 85 \mathrm{~mm}(300 \times 300$ DPI $)$ 
Table 1. Subject Data, net injected activity of $\left[{ }^{11} \mathrm{C}\right]-\mathrm{NE} 40$, and individual effective dose

$\begin{array}{cccccccc}\text { Subject } & \text { Sex } & \text { Age }(\mathrm{y}) & \begin{array}{c}\text { Height } \\ (\mathrm{cm})\end{array} & \begin{array}{c}\text { Mass } \\ (\mathrm{kg})\end{array} & \begin{array}{c}\text { Body mass } \\ \text { index } \\ \left(\mathrm{kg} / \mathrm{m}^{2}\right)\end{array} & \begin{array}{c}\text { Injected } \\ \text { activity } \\ (\mathrm{MBq})\end{array} & \begin{array}{c}\text { Individual } \\ (\mu \mathrm{SV} / \mathrm{MBq})\end{array} \\ \text { HV_1 } & \mathrm{M} & 20.8 & 178 & 61 & 19.3 & 302.3 & 3.93 \\ \text { HV_2 } & \text { M } & 44.9 & 187 & 90 & 25.7 & 201.2 & 2.79 \\ \text { HV_3 } & \text { M } & 24.2 & 186 & 86 & 24.8 & 254.8 & 3.05 \\ \text { HV_4 } & \text { M } & 65.3 & 166 & 61 & 22.1 & 310.1 & 5.09 \\ \text { HV_5 } & \text { M } & 61.0 & 187 & 90 & 25.7 & 324.1 & 3.46 \\ \text { HV_6 } & \text { M } & 22.6 & 192 & 82 & 22.2 & 325.8 & 3.54 \\ \text { Mean } \pm \text { SD } & & 39.8 \pm 20.1 & 182.7 \pm 9.3 & 78.3 \pm 13.8 & 23.3 \pm 2.6 & 286 \pm 49 & 3.64 \pm 0.81\end{array}$

HV: healthy volunteer, M: male, y: year, SD: standard deviation, ED: effective dose 
Table 2: Radiation absorbed dose estimate (OLINDA) Based on ICRP 30 gastrointestinal tract model

\begin{tabular}{|c|c|c|}
\hline Target Organ & $\begin{array}{c}\text { Mean Absorded Dose } \\
(\mu \mathrm{Gy} / \mathrm{MBq})\end{array}$ & $\begin{array}{c}\text { Coefficient of } \\
\text { variation } \\
(\%)\end{array}$ \\
\hline Adrenals & $2.7 \pm \pm 0.39 \underline{4}$ & 14.1 \\
\hline Brain & $2.73 \pm 0.84$ & 30.7 \\
\hline Breasts & $1 . \underline{5} 47 \pm 0.29 \underline{3}$ & 20.1 \\
\hline Gallbladder Wall & $5.8 z \pm 0.13$ & 21.8 \\
\hline Lower Large Intestine Wall & $2.6 z \pm 0.1 \theta$ & 38.8 \\
\hline Small Intestine & $15.6 \pm 1.03$ & 65.7 \\
\hline Stomach Wall & $2.26 \underline{3} \pm 0.514$ & 22.8 \\
\hline Upper large intestine Wall & $6.65 \underline{7} \pm 3.83$ & 57.6 \\
\hline Heart Wall & $7.0 z \pm 2.27 \underline{3}$ & 32.4 \\
\hline Kidneys & $6.657 \pm 1.53$ & 23.0 \\
\hline Liver & $11.5 \pm 1.15 \underline{2}$ & 10.0 \\
\hline Lungs & $4.01 \pm 0.697$ & 17.2 \\
\hline Muscle & $1.75 \underline{8} \pm 0.44$ & 23.4 \\
\hline Pancreas & $2.7 z \pm 0.43$ & 15.8 \\
\hline Red Marrow & $5.07 \underline{1} \pm 0.93$ & 18.4 \\
\hline Osteogenic Cells & $4.28 \underline{3} \pm 1.0 \theta$ & 23.4 \\
\hline Skin & $1.31 \pm 0.31$ & 23.5 \\
\hline Spleen & $6.04 \pm 1.31$ & 21.8 \\
\hline Testes & $1.4 z \pm 0.36 \underline{4}$ & 25.2 \\
\hline Thymus & $1.76 \underline{8} \pm 0.34$ & 19.3 \\
\hline Thyroid & $4.28 \underline{3} \pm 1.3 z$ & 30.9 \\
\hline Urinary Bladder Wall & $2.44 \pm 0.76 \underline{8}$ & 31.2 \\
\hline Uterus & $2.76 \underline{8} \pm 1.1 \theta$ & 39.7 \\
\hline Total Body & $2.4 \theta \pm 0.54$ & 21.3 \\
\hline Effective dose $(\mu \mathrm{Sv} / \mathrm{MBq})$ & $3.64 \mathrm{E} \pm 0.81$ & 22.3 \\
\hline
\end{tabular}


(SUPPLEMENTAL TABLES)

$\underline{\text { Whole-body biodistribution and radiation dosimetry of the cannabinoid type } 2 \text { receptor }}$ ligand $\left[{ }^{11} \mathrm{C}\right]-\mathrm{NE} 40$ in healthy subjects

Rawaha Ahmad, Michel Koole, Nele Evens, Kim Serdons, Alfons Verbruggen, Guy $\underline{\text { Bormans, Koen Van Laere }}$

To be submitted to: Molecular imaging and Biology

* Corresponding author:

Rawaha Ahmad, MD

Division of Nuclear Medicine E901

University Hospital Leuven

$\underline{\text { Herestraat } 49}$

B-3000 Leuven

Tel.: $+32-16-343715$

Fax: $+32-16-343759$

E-mail: rawaha.ahmad@uzleuven.be 
Supplemental Table 1: Time-integrated activity coefficients ( 'residence times' - in hours) for the individual subjects, as obtained by multiexponential curve fitting

Subject Nr.

Brain

Gallbladder

Lower Large Intestine

Small Intestines Upper Large Intestine Heart Wall

Kidneys

\section{Liver}

Lungs

Red Marrow

Spleen

Thyroid

Urinary Bladder

Remainder

$\begin{array}{rrrrrrrl}1 & 2 & 3 & 4 & 5 & 6 & \text { mean } & \text { SD } \\ 0.0145 & 0.0095 & 0.0136 & 0.0077 & 0.0098 & 0.0098 & 0.0108 & 0.002638 \\ 0.0002 & 0.0011 & 0.0015 & 0.0006 & 0.0006 & 0.0019 & 0.0010 & 0.000647 \\ & & & & & & & \\ 0.0001 & 0.0001 & 0.0001 & 0.0005 & 0.0002 & 0.0002 & 0.0002 & 0.000155 \\ 0.0320 & 0.0217 & 0.0301 & 0.1116 & 0.0413 & 0.0385 & 0.0459 & 0.032927 \\ & & & & & & & \\ 0.0038 & 0.0026 & 0.0036 & 0.0132 & 0.0049 & 0.0045 & 0.0054 & 0.003887 \\ 0.0042 & 0.0139 & 0.0074 & 0.0077 & 0.0060 & 0.0052 & 0.0074 & 0.003422 \\ 0.0046 & 0.0046 & 0.0065 & 0.0048 & 0.0057 & 0.0096 & 0.0060 & 0.001956 \\ 0.0613 & 0.0660 & 0.0819 & 0.0499 & 0.0729 & 0.0699 & 0.0670 & 0.010863 \\ 0.0099 & 0.0099 & 0.0113 & 0.0128 & 0.0140 & 0.0136 & 0.0119 & 0.001817 \\ 0.0275 & 0.0373 & 0.0310 & 0.0335 & 0.0380 & 0.0361 & 0.0339 & 0.004057 \\ 0.0026 & 0.0051 & 0.0032 & 0.0014 & 0.0048 & 0.0046 & 0.0036 & 0.001467 \\ 0.0002 & 0.0002 & 0.0003 & 0.0003 & 0.0006 & 0.0003 & 0.0003 & 0.000151 \\ 0.0011 & 0.0006 & 0.0013 & 0.0015 & 0.0004 & 0.0007 & 0.0009 & 0.000432 \\ 0.2569 & 0.2217 & 0.2014 & 0.2304 & 0.2033 & 0.2146 & 0.2214 & 0.020578\end{array}$


Supplemental table 2: Individual organ doses (OLINDA) (mGy/MBq) for the 6

Formatted: Line spacing: Double subjects (as defined in Table 1) of the study, and average organ doses derived from individual doses as well as based on mean kinetic parameters (time-integrated activity coefficients (TIAC)) and their relative difference $(\%)$.

\begin{tabular}{|c|c|c|c|c|c|c|}
\hline \multicolumn{7}{|l|}{ Subject } \\
\hline \multirow[t]{2}{*}{ Ar. } & 1 & $z$ & 3 & 4 & 5 & \\
\hline & $3.21 E$ & $2.38 E$ & Z.47E & $3.18 E$ & Z.38E- & $2.64 E$ \\
\hline \multirow[t]{2}{*}{ Adrenals } & $\theta 3$ & $\theta 3$ & $\theta 3$ & $\theta 3$ & $\theta 3$ & $\theta 3$ \\
\hline & $4.31 \mathrm{E}$ & $2.11 E$ & 2.97E & 2.47E- & $2.15 E$ & $2.34 \mathrm{E}$ \\
\hline \multirow[t]{2}{*}{ Brain } & $\theta 3$ & $\theta 3$ & $\theta 3$ & $\theta 3$ & $\theta 3$ & $\theta 3$ \\
\hline & $1.89 E$ & $1.31 E$ & $1.25 E$ & $1.80 E-$ & $1.22 \mathrm{E}$ & 1.35E \\
\hline ceasts & 03 & $\theta 3$ & 03 & 03 & 03 & 03 \\
\hline allbladd & 4.50E- & 5.36E- & $6.66 \mathrm{E}$ & $6.21 E$ & 4.49E- & $7.68 E$ \\
\hline \multirow[t]{2}{*}{ er Wall } & $\theta 3$ & $\theta 3$ & $\theta 3$ & $\theta 3$ & $\theta 3$ & $\theta 3$ \\
\hline & $2.91 E$ & $1.88 E$ & $1.93 E$ & $4.55 E-$ & $2.14 E$ & $2.31 \mathrm{E}$ \\
\hline W Wall & 03 & 03 & 03 & 03 & 03 & 03 \\
\hline Aall & $1.22 E$ & 8.05E & $1.05 E$ & $3.62 E$ & 1.37E- & $1.32 E$ \\
\hline testine & $\theta z$ & $\theta 3$ & $\theta z$ & $\theta z$ & $\theta z$ & $\theta 2$ \\
\hline$\theta m=$ & $2.71 \mathrm{E}$ & $1.89 E$ & $1.88 \mathrm{E}$ & $3.08 \mathrm{E}-$ & 1.89E- & Z.09E- \\
\hline \multirow[t]{2}{*}{ Wall } & $\theta 3$ & $\theta 3$ & $\theta 3$ & $\theta 3$ & $\theta 3$ & 03 \\
\hline & $5.92 E$ & $3.80 E-$ & $4.65 E$ & $1.43 E$ & $5.61 E$ & $5.61 \mathrm{E}$ \\
\hline HWall & 03 & 03 & 03 & $\theta 2$ & 03 & 03 \\
\hline eart & $5.65 E$ & 1.06E- & $6.45 E$ & $9.05 E-$ & $5.25 E-$ & $5.13 E$ \\
\hline \multirow[t]{2}{*}{ Wall } & $\theta 3$ & $\theta z$ & $\theta 3$ & $\theta 3$ & $\theta 3$ & $\theta 3$ \\
\hline & $6.62 E$ & $4.73 E$ & $6.42 E$ & $7.25 E$ & 5.64E- & $9.22 \mathrm{E}$ \\
\hline \multirow[t]{2}{*}{ Kidneys } & 03 & 03 & 03 & 03 & 03 & 03 \\
\hline & $1.31 E$ & $9.95 E$ & $1.26 E$ & $1.12 E$ & 1.09E- & 1.14E \\
\hline \multirow[t]{2}{*}{ tiver } & $\theta z$ & $\theta 3$ & $\theta z$ & $\theta z$ & $\theta z$ & $\theta z$ \\
\hline & $4.26 \mathrm{E}-$ & $3.12 \mathrm{E}$ & $3.49 E$ & $5.11 E$ & $3.90 E-$ & 4.15E \\
\hline \multirow[t]{2}{*}{ tungs } & $\theta 3$ & 03 & $\theta 3$ & $\theta 3$ & $\theta 3$ & $\theta 3$ \\
\hline & $2.21 \mathrm{E}$ & 1.47E- & $1.45 E$ & Z.33E- & 1.44E- & $1.60 \mathrm{E}$ \\
\hline \multirow[t]{2}{*}{ Muscle } & 03 & 03 & 03 & 03 & $\theta 3$ & 03 \\
\hline & $3.28 \mathrm{E}-$ & 2.07E- & $2.20 E$ & 5.39E- & $Z .40 E$ & $2.58 \mathrm{E}$ \\
\hline \multirow[t]{2}{*}{ Ovaries } & $\theta 3$ & 03 & $\theta 3$ & $\theta 3$ & $\theta 3$ & $\theta 3$ \\
\hline & $3.21 \mathrm{E}$ & Z.39E & $2.42 E$ & $3.31 E$ & Z.37E- & $2.62 E$ \\
\hline ancreas & 03 & 03 & 03 & 03 & 03 & 03 \\
\hline$d$ & $5.63 E$ & $4.50 E$ & $4.13 E$ & $6.67 E$ & 4.59E- & $4.89 E$ \\
\hline larrow & $\theta 3$ & $\theta 3$ & $\theta 3$ & $\theta 3$ & 03 & $\theta 3$ \\
\hline Osteogeni & $5.40 E$ & $3.64 E-$ & $3.40 E$ & 5.70E- & $3.60 \mathrm{E}-$ & $3.96 E$ \\
\hline \multirow[t]{2}{*}{$\in$ Cells } & $\theta 3$ & $\theta 3$ & $\theta 3$ & $\theta 3$ & $\theta 3$ & $\theta 3$ \\
\hline & $1.73 E$ & $1.11 E$ & 1.09E & 1.67E- & $1.06 \mathrm{E}$ & $1.19 \mathrm{E}$ \\
\hline & 03 & 03 & 03 & 03 & 03 & 03 \\
\hline teen & $5.85 \mathrm{E}-$ & 7.16E- & 5.05E- & 3.97E- & $6.82 \mathrm{E}-$ & $7.23 \mathrm{E}-$ \\
\hline
\end{tabular}

Formatted Table 


\begin{tabular}{|c|c|c|c|c|c|}
\hline$\theta 3$ & $\theta 3$ & $\theta 3$ & $\theta 3$ & $\theta 3$ & \\
\hline $22 E-$ & $1.21 \mathrm{E}-$ & 1.15E- & $1.83 E$ & $1.13 \mathrm{E}$ & 1.28 \\
\hline 03 & $\theta 3$ & 03 & $\theta 3$ & $\theta 3$ & \\
\hline $22 \mathrm{E}$ & $1.63 E-$ & 1.49E- & $2.15 \mathrm{E}-$ & $1.45 E-$ & 1.6 \\
\hline$\theta 3$ & $\theta 3$ & $\theta 3$ & $\theta 3$ & $\theta 3$ & \\
\hline $33 E-$ & Z.65E- & $3.70 E-$ & $5.14 E$ & $6.43 E-$ & 3.9 \\
\hline$\theta 3$ & $\theta 3$ & $\theta 3$ & $\theta 3$ & $\theta 3$ & \\
\hline 25E- & $1.85 E$ & $2.29 E$ & $3.67 \mathrm{E}$ & $1.72 \mathrm{E}$ & 2.0 \\
\hline$\theta 3$ & $\theta 3$ & $\theta 3$ & $\theta 3$ & $\theta 3$ & \\
\hline $2 \mathrm{E}$ & 1.95E- & $2.07 \mathrm{E}-$ & $4.84 \mathrm{E}-$ & $2.21 \mathrm{E}-$ & 2.3 \\
\hline$\theta 3$ & $\theta 3$ & $\theta 3$ & $\theta 3$ & $\theta 3$ & \\
\hline 37E- & 1.99E- & $2.06 \mathrm{E}-$ & $3.20 \mathrm{E}-$ & 2.04E- & 2.23 \\
\hline$\theta 3$ & 03 & 03 & 03 & 03 & \\
\hline & 0.0027 & 0.0030 & 0.0050 & 0.0034 & 0.0 \\
\hline 3 & 9 & 5 & 9 & 6 & \\
\hline
\end{tabular}

Subject

$\mathrm{Nr}$.

\section{Adrenals}

Brain

Breasts

Gallbladd er Wall

LLI Wall

Small Intestine Stomach

Wall

ULI Wall Heart

Wall

$\underline{\text { Kidneys }}$

Liver

Lungs

Muscle

$\underline{\text { Ovaries }}$

$\begin{array}{lllllll} & 1 & \underline{2} & \underline{3} & \underline{4} & \underline{5} & \underline{6}\end{array}$

$21 \mathrm{E}$

$\underline{03}$

$\underline{4.31 \mathrm{E}}$

$\underline{2.38 \mathrm{E}-}$

2.47E

E-

$\underline{3.18 \mathrm{E}-} \quad \underline{2.38 \mathrm{E}-} \quad \underline{2.64 \mathrm{E}-}$

$2.11 \overline{\mathrm{E}}-2 \underline{03 \mathrm{E}-} \quad \underline{03}$

1.89

03

$\underline{03}$

$\frac{03}{1 \mathrm{E}-}$

2.97E-

$2.47 \mathrm{E}$

3

$1.25 \mathrm{E}-\quad 1.80 \mathrm{E}-$

$4.50 \mathrm{E}-$

$\underline{03}$

$2.91 \mathrm{E}$

$1.22 \mathrm{E}$

$\underline{02}$

2.71E

$5.92 \mathrm{E}$

03.92

$5.65 \mathrm{E}$

$\underline{03}$

6.62E-

$1.31 \mathrm{E}$

$\frac{1.31 \mathrm{E}}{02}$

4.26E

2 03

2.21E-

$3.28 \mathrm{E}$

5.36

$\frac{03}{6 \mathrm{E}-}$

6.66E-

$6.21 \mathrm{E}-$

$\frac{6.21 \mathrm{E}-}{\underline{03}}$

$\frac{1.88 \mathrm{E}-}{03} \quad \frac{1.93 \mathrm{E}-}{\underline{03}} \quad \underline{4.55 \mathrm{E}-}$

$\underline{8.05 \mathrm{E}-} \quad \underline{1.05 \mathrm{E}-} \quad \underline{3.62 \mathrm{E}-}$

$\frac{3.62 \mathrm{E}-}{\underline{02}}$

$\begin{array}{rrr}1.89 \mathrm{E}- & 1.88 \mathrm{E}- & 3.08 \mathrm{E}- \\ \underline{03} & \underline{03}\end{array}$

$\underline{3.80 \mathrm{E}-} \quad \underline{4.65 \mathrm{E}-} \quad \underline{1.43 \mathrm{E}-}$

$\underline{1.43 \mathrm{E}-}$

$\frac{1.06 \mathrm{E}-}{\underline{02}} \quad \frac{6.45 \mathrm{E}-}{\underline{03}} \quad \underline{9.05 \mathrm{E}-}$

$\underline{4.73 \mathrm{E}-} \quad \underline{6.42 \mathrm{E}-} \quad \underline{7.25 \mathrm{E}-}$

$\frac{7.25 \mathrm{E}-}{\underline{03}}$

$1.12 \mathrm{E}-$

$\frac{9.95 \mathrm{E}-}{03}$

$1.26 \mathrm{E}$

02

5.11E-

$2.15 \mathrm{E}-$

$\underline{03}$

$1.22 \mathrm{E}-1 . \underline{03}$

$\underline{03} \quad \underline{03}$

4.49E- 7.68E-

$2.14 \mathrm{E}-\quad 2.31 \mathrm{E}-$

$\frac{2.14 \mathrm{E}-}{\underline{03}} \quad \frac{2.31 \mathrm{E}-}{\underline{03}}$

$\frac{1.37 \mathrm{E}-}{02} \quad \underline{1.32 \mathrm{E}-}$

$\underline{1.89 \underline{\mathrm{E}}-} \quad \underline{02} \quad \underline{02}$

$\underline{5.61 \mathrm{E}-} \quad \underline{03} \underline{03}$

$$
\underline{03} \quad \underline{03}
$$

$\frac{5.25 \mathrm{E}-}{03} \quad \frac{5.13 \mathrm{E}-}{03}$

$\frac{5.64 \mathrm{E}-}{\underline{03}} \quad \frac{9.22 \mathrm{E}-}{\underline{03}}$

$\frac{1.09 \mathrm{E}-}{02} \quad \frac{1.14 \mathrm{E}-}{02}$

3.90E- $\quad \underline{4.15 \mathrm{E}-}$

$\underline{03}$

$\underline{03}$

$\underline{1.47 \mathrm{E}-} \quad \underline{03} \quad \underline{03} \underline{\underline{03}-} \quad \underline{2.33 \mathrm{E}-}$

$\frac{1.47 \mathrm{E}}{\underline{03}}$

$\underline{3}$ $\frac{1.44 \mathrm{E}-}{\underline{03}} \quad \underline{1.60 \mathrm{E}-}$

$\frac{2.40 \mathrm{E}-}{\underline{03}} \quad \underline{2.58 \mathrm{E}-}$

\section{mean bsorbe d dose}

organ relative from $\underline{\mathrm{e}}$ $\underline{\text { mean }}$

$\underline{\text { TIAC }}$

$\underline{2.71 \mathrm{E}-} \quad \underline{2.78 \mathrm{E}-} \quad \underline{2.52 \%}$

2.79E-

$\underline{2.33 \%}$

$1.47 \mathrm{E}-\quad 1.51 \mathrm{E}-\quad 2.65 \%$

$\underline{5.82 \mathrm{E}-} \quad \underline{5.95 \mathrm{E}-}$

$2.62 \mathrm{E}-\quad \underline{03} \quad \underline{03}$

$\frac{.63}{03} \quad \underline{03}$

$\underline{1.56 \mathrm{E}-} \quad \underline{1.57 \mathrm{E}-}$

$\underline{02} \quad \underline{02}$

$\underline{2.26 \mathrm{E}-} \quad 2.30 \mathrm{E}-$

$6.65 \mathrm{E}-\quad \underline{03} \quad \underline{03}$

$\underline{03} \quad \underline{03}$

$\underline{7.02 \mathrm{E}-} \quad 7.40 \mathrm{E}-$

$6.65 \overline{\mathrm{E}}-\quad \underline{03} \quad \underline{03}$

$\underline{03} \quad \underline{03}$

$\frac{1.15 \mathrm{E}-}{02} \quad \frac{1.21 \mathrm{E}-}{02}$

4.01E- $\quad 4.14 \mathrm{E}-$

$\underline{03} \quad \underline{03}$

$\frac{1.75 \mathrm{E}-}{03} \quad \underline{1.78 \mathrm{E}-}$

$\frac{2.99 \mathrm{E}-}{\underline{03}} \quad \underline{3.00 \mathrm{E}-}$
$2.24 \%$

$\underline{0.76 \%}$

$\underline{0.37 \%}$

$1.88 \%$

$\underline{-0.13 \%}$

$\underline{5.11 \%}$

$\underline{4.50 \%}$

$\underline{4.75 \%}$

$\underline{3.26 \%}$

$1.69 \%$

$\underline{0.44 \%}$ 


\begin{tabular}{|c|c|c|c|c|c|c|c|c|c|}
\hline Panc & $\frac{21 \mathrm{E}-}{\underline{03}}$ & $\frac{.39 \mathrm{E}-}{03}$ & $\frac{2.42 \mathrm{E}-}{\underline{03}}$ & $\frac{3.31 \mathrm{E}-}{\underline{03}}$ & $\frac{37 \mathrm{E}-}{\underline{03}}$ & $\frac{62 \mathrm{E}-}{\underline{03}}$ & $\frac{.72 \mathrm{E}-}{\underline{03}}$ & $\frac{2.78 \mathrm{E}-}{\underline{03}}$ & $.16 \%$ \\
\hline Red & $5.63 \mathrm{E}-$ & $4.50 \mathrm{E}-$ & $4.13 \mathrm{E}-$ & $6.67 \mathrm{E}-$ & $4.59 \mathrm{E}-$ & $4.89 \mathrm{E}-$ & $5.07 \mathrm{E}-$ & $5.24 \mathrm{E}-$ & $3.28 \%$ \\
\hline arrow & $\underline{03}$ & $\underline{03}$ & $\underline{03}$ & $\underline{03}$ & $\underline{03}$ & $\underline{03}$ & $\underline{03}$ & $\underline{03}$ & \\
\hline Osteogeni & $.40 \mathrm{E}-$ & $3.64 \mathrm{E}-$ & $3.40 \mathrm{E}-$ & $5.70 \mathrm{E}-$ & $3.60 \mathrm{E}-$ & $3.96 \mathrm{E}-$ & $4.28 \mathrm{E}-$ & 4.40E- & .6 \\
\hline c Cells & $\underline{03}$ & $\underline{03}$ & $\underline{03}$ & $\underline{03}$ & $\underline{03}$ & $\underline{03}$ & $\underline{03}$ & $\underline{03}$ & \\
\hline & $\underline{1.73 \mathrm{E}-}$ & $1.11 \mathrm{E}-$ & $1.09 \mathrm{E}-$ & $1.6 \overline{\mathrm{E}-}$ & $1.06 \bar{E}-$ & $1.19 \overline{\mathrm{E}}-$ & $1.3 \overline{\mathrm{E}-}$ & $1.33 \mathrm{E}-$ & $1.63 \%$ \\
\hline Skin & $\underline{03}$ & $\underline{03}$ & $\underline{03}$ & $\underline{03}$ & $\underline{03}$ & $\underline{03}$ & $\underline{03}$ & $\underline{03}$ & \\
\hline & 5.85E- & 7.16E- & 5.05E- & $3.9 \overline{\mathrm{E}-}$ & $6.82 \overline{\mathrm{E}}-$ & $7.23 \overline{\mathrm{E}}-$ & $6.01 \overline{\mathrm{E}}-$ & $6.45 \bar{E}-$ & $.77 \%$ \\
\hline Spleen & & $\underline{03}$ & $\underline{03}$ & $\underline{03}$ & $\underline{03}$ & 03 & $\underline{03}$ & $\underline{03}$ & \\
\hline & $\underline{1.92 \mathrm{E}-}$ & $\underline{1.21 \mathrm{E}-}$ & $\underline{1.15 \mathrm{E}-}$ & $\underline{1.83 \overline{\mathrm{E}}-}$ & $1.13 \mathrm{E}-$ & $1.28 \mathrm{E}-$ & $1.42 \mathrm{E}-$ & $1.45 \mathrm{E}-$ & $.07 \%$ \\
\hline$\underline{\text { Testes }}$ & 0 & $\underline{03}$ & $\underline{03}$ & $\underline{03}$ & $\underline{03}$ & - & $\underline{03}$ & $\underline{03}$ & \\
\hline & $\underline{2.22 \mathrm{E}-}$ & $\underline{1.63 \mathrm{E}-}$ & $\underline{1.49 \mathrm{E}-}$ & $2.15 \mathrm{E}-$ & $1.45 \mathrm{E}$ & $\underline{1.60 \mathrm{E}}$ & $.76 \mathrm{E}-$ & $1.80 \mathrm{E}-$ & $41 \%$ \\
\hline aymus & $\underline{03}$ & $\underline{03}$ & $\underline{03}$ & $\underline{03}$ & $\underline{03}$ & $0 x$ & & 03 & \\
\hline & $3.83 \mathrm{E}-$ & $2.65 \mathrm{E}-$ & $3.70 \mathrm{E}-$ & $5.14 \mathrm{E}-$ & $\underline{6.43 \mathrm{E}-}$ & $3.90 \mathrm{E}-$ & $4.28 \mathrm{E}-$ & $\underline{4.31 \mathrm{E}-}$ & $.81 \%$ \\
\hline Thyroid & 0 & $\underline{03}$ & $\underline{03}$ & $\underline{03}$ & $\underline{03}$ & $\underline{03}$ & $\underline{03}$ & $\underline{03}$ & \\
\hline Urinary & & & & & & & $2.44 \mathrm{E}-$ & $2.44 \mathrm{E}-$ & \\
\hline Bladder & $\underline{3.05 \mathrm{E}-}$ & $\underline{1.85 \mathrm{E}-}$ & $2.29 \mathrm{E}-$ & $3.67 \mathrm{E}-$ & $1.72 \mathrm{E}-$ & $\underline{2.08 \mathrm{E}-}$ & $\underline{03}$ & $\underline{03}$ & \\
\hline$\underline{\text { Wall }}$ & & & $\underline{03}$ & $\underline{03}$ & $\underline{03}$ & $\underline{03}$ & & & \\
\hline & $12 \mathrm{E}-$ & $\underline{1.95 \mathrm{E}-}$ & 2.07E- & $4.84 \mathrm{E}-$ & $2.21 \mathrm{E}-$ & $2.39 \mathrm{E}-$ & $2.76 \mathrm{E}-$ & $\underline{2.78 \mathrm{E}-}$ & .6 \\
\hline terus & o & $\underline{0} 3$ & $\underline{03}$ & $\underline{03}$ & o & $\underline{03}$ & $\underline{03}$ & $\underline{03}$ & \\
\hline Total & 2.87E- & $1.99 \mathrm{E}-$ & $2.06 \mathrm{E}-$ & $3.20 \mathrm{E}-$ & $2.04 \mathrm{E}-$ & $2.23 \mathrm{E}-$ & 2.40E- & $2.46 \mathrm{E}-$ & $2.51 \%$ \\
\hline Body & $\underline{03}$ & $\underline{03}$ & $\underline{03}$ & $\underline{03}$ & $\underline{03}$ & $\underline{03}$ & $\underline{03}$ & $\underline{03}$ & \\
\hline & $\underline{0.003}$ & $\frac{0.0027}{9}$ & $\frac{.0030}{5}$ & 0.0050 & .0034 & $\underline{0.0035}$ & .00364 & $\underline{0.0038}$ & $5.86 \%$ \\
\hline
\end{tabular}

